\title{
Application of tube-type ceramic microfiltration membrane for post-treatment of effluent from biological wastewater treatment process using phase separation
}

\author{
Dong-Jin Son ${ }^{1}$, Woo-Yeol Kim², Chan-Young Yun², Dae-Gun Kim³ , Duk Chang', \\ Young Sunwoo ${ }^{2}$, Ki-Ho Hong $^{4+}$ \\ ${ }^{1}$ Department of Advanced Technology Fusion, Konkuk University, Seoul 05029, Republic of Korea \\ ${ }^{2}$ Department of Environmental Engineering, Konkuk University, Seoul 05029, Republic of Korea \\ ${ }^{3}$ Materials \& Membranes Co., Ltd., Gwahakdanji-ro, Gangneung 25440, Republic of Korea \\ ${ }^{4}$ Division of Interdisciplinary Studies, Konkuk University, Seoul 05029, Republic of Korea
}

\section{ABSTRACT}

A tube-type ceramic membrane for microfiltration was developed, and the membrane module comprised of three membranes was also applied to biological carbon and nitrogen removal processes for post-treatment. Manufacturing the microfiltration membrane was successful with the structure and boundary of the coated and support layers within the membrane module clearly observable. Total kjeldahl nitrogen removal from effluent was additionally achieved through the elimination of solids containing organic nitrogen by use of the ceramic membrane module. Removal of suspended solids and colloidal substances were noticeably improved after membrane filtration, and the filtration function of the ceramic membrane could also easily be recovered by physical cleaning. By using the ceramic membrane module, the system showed average removals of organics, nitrogen, and solids up to $98 \%, 80 \%$ and $99.9 \%$, respectively. Thus, this microfiltration system appears to be an alternative and flexible option for existing biological nutrient removal processes suffering from poor settling performance due to the use of a clarifier.

Keywords: Alternating flow, Ceramic membrane, Intermittent aeration, Post-treatment, Wastewater treatment

\section{Introduction}

In general, nutrients such as nitrogen and phosphorus in wastewater are well known as major factors encouraging growth of algae which cause eutrophication in aquatic ecosystems. It can lead to oxygen exhaustion in water bodies, reduction in species diversity, and taste, odor, and water treatment problems [1-3]. Therefore, removal of nitrogen and phosphorus is absolutely necessary for protection of water resources from eutrophication [4]. Eutrophication can be prevented by the control of either nitrogen or phosphorus [5].

Nutrient removal from wastewater is generally achieved by physical, chemical, and/or biological treatments. Among these, biological treatments have advantages associated with disposal of produced sludge, and its maintenance costs can be more economical and sustainable than other treatment methods [6]. Numerous studies on the biological nutrient removal (BNR) process have been carried out. Most notably, phase separation technology adopting intermittent aeration and flow path change has been widely used and applied [7-10]. This technology has some advantages: (1) elimination of the need for internal recirculation of sludge and nitrified effluent, (2) higher process flexibility by controlling each phase to match the fluctuation of influent loads, and so on. In spite of their many advantages, however, phase separation technology has the limitation of poor settling performance due to the use of a clarifier like any other biological process.

Membrane separation is a remarkable technology that overcomes the settling problems in general biological wastewater treatment. Membrane separation has many merits such as stable purified effluent quality, small area requirement, and relatively lower sensitivity

Received February 2, 2017 Accepted May 8, 2017

${ }^{\dagger}$ Corresponding author

Email: khhong@konkuk.ac.kr (or khhong0221@gmail.com) Tel: +82-2-450-4047 Fax: +82-2-2201-6392 mits unrestricted non-commercial use, distribution, and
medium, provided the original work is properly cited.

Copyright (C) 2017 Korean Society of Environmental Engineers 
to fluctuation as a consequence of higher biomass concentration $[11,12]$. In particular, membranes made of ceramic materials have been emerging as a promising technology due to its inert characteristics, thermal stability, resistance to acids and strong solvents, and relatively narrow pore size distribution with higher porosity [13-19]. Ceramic membranes can be applied under conditions of higher permeate flux, and it can reduce chemical cleaning periods caused by fouling $[15,18]$. They are also more economical in the long-term operation due to lower operation costs [14].

In this study, a tube-type ceramic microfiltration membrane having chemical, thermal, and mechanical stability and a relatively long working life was developed to overcome the disadvantages of organic polymeric membranes. The membrane module comprised of three tube-type ceramic membranes was also applied to biological phase separation processes for enhanced removal of carbon and nitrogen, and its performance was evaluated. The filtration function and recovery characteristics of the ceramic membrane manufactured in this study were also evaluated.

\section{Materials and Methods}

The biological phase separation system adopting flow path change and intermittent aeration is composed of two reactors and a clarifier, and it is combined with a ceramic microfiltration membrane module, as shown in Fig. 1. The residual particulate contaminants such as suspended solids (SS) and colloidal substances discharged from the clarifier were separated by membrane filtration.

\subsection{Biological Wastewater Treatment Process Using Phase Separation}

The two reactors in the biological process have a total liquid volume of $11.2 \mathrm{~L}$ and each reactor is $150 \mathrm{~mm}$ long and $100 \mathrm{~mm}$ wide with a height of $300 \mathrm{~mm}$. The solenoid valves for alternating flow and aerators for intermittent aeration are operated by a programmable logic controller. Nitrogen removal in biological phase separation is carried out by rotating aerobic and anoxic phases during four different steps. Phase separations can be accomplished by adopting intermittent aeration and alternating flows between the two reactors.

The operational sequence is comprised of four steps A, B, $\mathrm{C}$, and $\mathrm{D}$ in series for one complete cycle of operation. These four steps may be divided into two main steps A and C, and two intermediate steps B and D. Steps C and D are mirror images of steps A and B. In step A, one reactor is in aerobic phase and the other in anoxic phase. During the aerobic phase, nitrification reactions occur and residual organics can be removed. During the anoxic phase, denitrification reactions take place and influent organics are supplied continuously as a carbon source. In step B, both reactors are in aerobic phase. Each phase length can be changed to achieve a particular treatment purpose. In this study, the time for one complete cycle comprising of the four steps was $4 \mathrm{~h}$. Time lengths for aerobic and anoxic phases were $2.5 \mathrm{~h}$ and $1.5 \mathrm{~h}$, respectively. The system was inoculated with activated sludge from a municipal wastewater treatment plant in Seoul, Korea. Also, the biological process was operated at a hydraulic retention time (HRT) of $8 \mathrm{~h}$ and a solid retention time (SRT) of $20 \mathrm{~d}$.

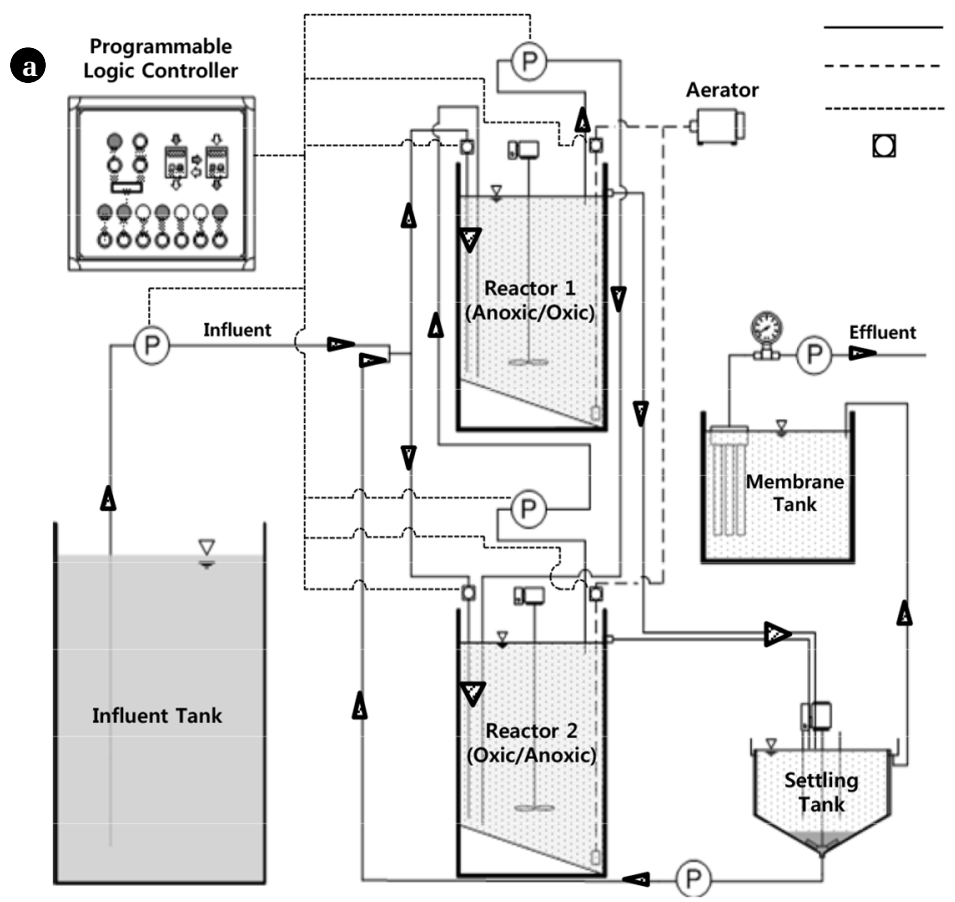

Water line

Air line

Control line

Solenoid valve

Fig. 1. Schematic diagram of (a) combined biological phase separation process with ceramic membrane (b) Tube-type ceramic membrane. 
Table 1. Effluent Characteristics after Biological Phase Separation Process and Microfiltration

\begin{tabular}{|c|c|c|c|}
\hline \multicolumn{2}{|l|}{ Parameters } & Effluent from biological phase separation process* & Effluent from microfiltration* \\
\hline \multicolumn{2}{|c|}{ Total Suspended Solids (mg/L) } & $0.2-1.6(0.7 \pm 0.3)$ & $0.0-0.1(0.1 \pm 0.1)$ \\
\hline \multicolumn{2}{|c|}{ Turbidity (NTU) } & $1.0-3.5(2.0 \pm 0.7)$ & $0.5-0.9(0.7 \pm 0.1)$ \\
\hline \multirow{2}{*}{$\begin{array}{l}\text { Chemical Oxygen Demand } \\
\qquad(\mathrm{mg} / \mathrm{L})\end{array}$} & Total & $4-28(12 \pm 6)$ & $0-7(4 \pm 2)$ \\
\hline & Soluble & $0-24(8 \pm 6)$ & $0-7(3 \pm 2)$ \\
\hline \multicolumn{2}{|c|}{ Total Kjeldahl Nitrogen (mg/L) } & $0.0-2.2(0.7 \pm 0.6)$ & $0.0-0.8(0.2 \pm 0.3)$ \\
\hline \multicolumn{2}{|c|}{ Ammonia (mg/L) } & $0.0-2.0(0.4 \pm 0.6)$ & $0.0-0.6(0.1 \pm 0.2)$ \\
\hline \multicolumn{2}{|c|}{ Nitrate $(\mathrm{mg} / \mathrm{L})$} & $4.64-11.48(7.00 \pm 1.93)$ & $5.63-6.55(5.88 \pm 0.29)$ \\
\hline
\end{tabular}

${ }^{*}$ minimum-maximum (average \pm std.)

\subsection{Preparation of Tubular-type Ceramic Microfiltration Membrane}

For the manufacturing of a tube-type ceramic membrane, a mixture of poly methyl methacrylate (PMMA) powder, $20 \mu \mathrm{m}$ in particle size, and $\alpha$-alumina $\left(\alpha-\mathrm{Al}_{2} \mathrm{O}_{3}\right)$ powder, having a particle size of $5 \mu \mathrm{m}$, was blended with a cellulose binder of $27 \mathrm{wt} \%$ into a paste, and it was shaped into a tube by extrusion molding and used as a support layer for the membrane. To eliminate the cellulose binder, the extruded and dried paste was sintered under conditions of $300^{\circ} \mathrm{C}, 500^{\circ} \mathrm{C}$ and $1,500^{\circ} \mathrm{C}$, in three consecutive steps. It was also coated with a spray of slurry which contained $\alpha$-alumina powder, $0.5 \mu \mathrm{m}$ in particle size, for formation of microfiltration permeability, and then re-sintered reaching $1,200^{\circ} \mathrm{C}$. Thus, the manufactured tube-type ceramic membrane is constructed with a coated layer for filtration and a support layer for collection of filtrate, which supports the coated layer structurally. The thickness of coated and support layers were $20 \mu \mathrm{m}$ and $3.5 \mathrm{~mm}$, respectively. Specific volume was also measured by mercury porosimetry method to confirm the actual pore size distribution in the manufactured ceramic membrane.

\subsection{Ceramic Microfiltration Membrane Module}

The ceramic microfiltration membrane module consists of three tube-type membranes, and the surface area of each individual membrane is $72.2 \mathrm{~cm}^{2}$. The module was installed subsequent to the secondary clarifier in the biological treatment process for post-treatment of effluent and operated in a dead-end filtration manner with a peristaltic pump (Model No. 7553-75, Cole-Parmer Instrument Company, USA). A pressure gauge was also installed for measurement of transmembrane pressure (TMP).

\subsection{Preparation of Feed Water and Analytical Methods}

Synthetic feed, representing typical organic and nitrogen concentrations of domestic wastewater in Korea, was prepared and used. The chemical oxygen demand (COD), total kjeldahl nitrogen (TKN), and ammonia of the synthetic wastewater ranged between 135-230 $\mathrm{mg} / \mathrm{L}$ (average $200 \mathrm{mg} / \mathrm{L}$ ), 24.6-36.4 mg/L (average $33.0 \mathrm{mg} / \mathrm{L}$ ), and 20.2-32.8 mg/L (average $29.0 \mathrm{mg} / \mathrm{L}$ ), respectively. The effluent characteristics after biological phase separation process and microfiltration were summarized in Table 1 . All analyses were conducted as per procedures outlined in the American Public Health Association (APHA) Standard Methods [20].

\section{Results and Discussion}

\subsection{Evaluation of Manufactured Ceramic Membrane}

Fig. 2 shows a cross-sectional scanning electron micrograph and pore size distribution of the tube-type ceramic membrane manufactured in this study. The structure of the microfiltration membrane is composed of coated and support layers with a thickness of $20 \mu \mathrm{m}$ and $3.5 \mathrm{~mm}$, respectively. As we can see from the cross-sectional micrograph, the boundary of each layer can be clearly observed. The actual pore size distribution in the manufactured ceramic membrane was measured and confirmed by the mercury porosimetry method. As presented in Fig. 2, pore diameters of both the coated and support layers of the membrane were in the range of 0.1-0.2 $\mu \mathrm{m}$ and 2-5 $\mu \mathrm{m}$, respectively. This means that a ceramic microfiltration membrane can be manufactured successfully by coating $\alpha$-alumina powder for formation of a microfiltration layer.

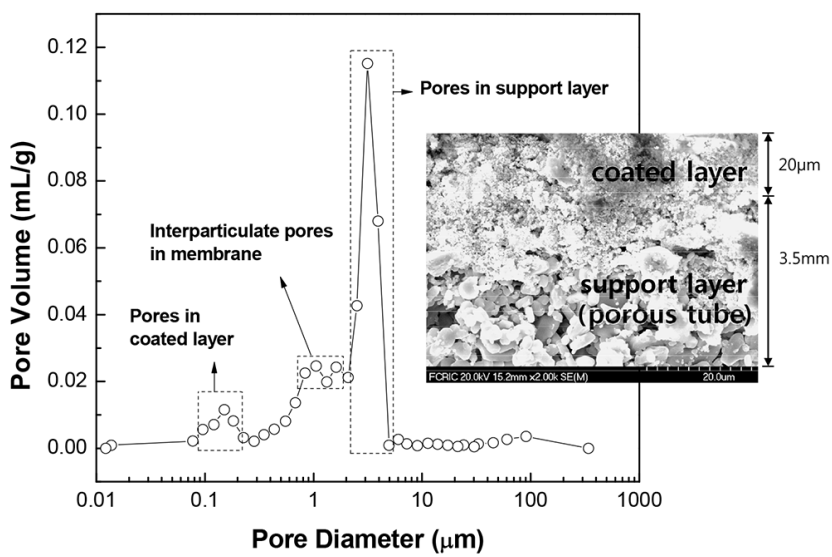

Fig. 2. Pore distribution and SEM of ceramic membrane.

\subsection{Organic Removal Characteristics}

Fig. 3 presents the COD removal characteristics of the biological phase separation process adopting flow path change and intermittent aeration before and after application of the ceramic microfiltration membrane module. Under the condition of an HRT of $8 \mathrm{~h}$ and a cycle time of $4 \mathrm{~h}$, the concentrations of total COD (TCOD) 


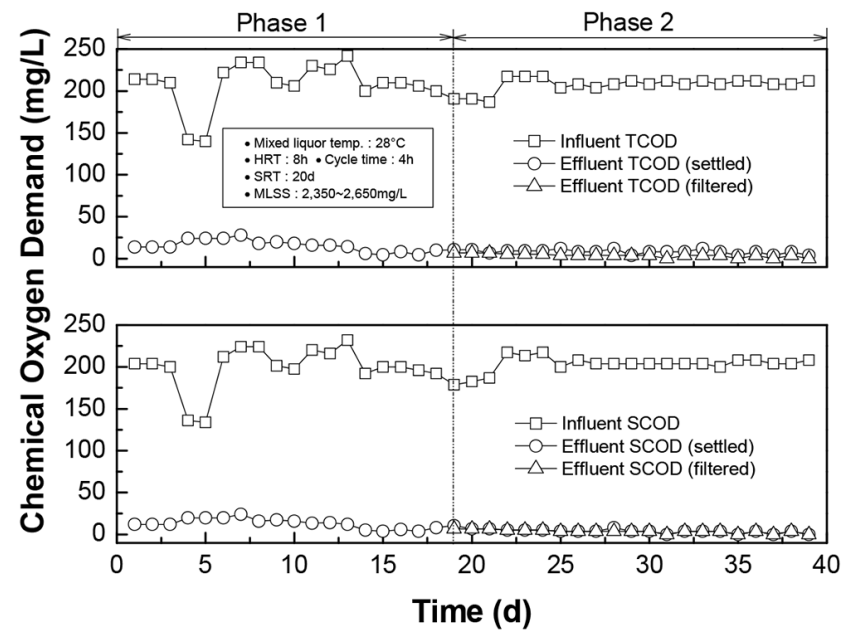

Fig. 3. Organics removal characteristics of system.

(Phase 1: system before membrane module application, Phase 2: system after membrane module application)

and soluble COD (SCOD), which represents the dissolved organics in the effluent from the biological phase separation process, were observed to be in the range of 4-28 mg/L (average $11.5 \mathrm{mg} / \mathrm{L}$ ) and 0-24 mg/L (average $8.3 \mathrm{mg} / \mathrm{L}$ ), respectively. However, this process combined with the ceramic microfiltration membrane module was capable of producing effluent TCOD and SCOD ranging 0-6.7 mg/L (average $3.8 \mathrm{mg} / \mathrm{L}$ ) for the same operating conditions. Residual solids and colloidal substances in the effluent could be additionally removed by membrane filtration thereby improving the process stability. Cases of such successful additional separation of remaining solids and colloids in effluent by membrane filtration have been reported elsewhere [21-23].

\subsection{Nitrogen Removal Characteristics}

Biological nitrogen removal processes are generally classified as post-denitrification or pre-denitrification, depending on the process configuration. Post-denitrification can be achieved with a serial step after nitrification, requiring an external carbon source supply. Pre-denitrification, where the denitrification reactor precedes the nitrification reactor, achieves nitrogen removal without external carbon source addition. This process requires a recycling of nitrified effluent to an anoxic reactor where it mixes with the influent.

During the anoxic phase in the biological phase separation adopting flow path change and intermittent aeration used in this study, however, influent organics such as COD may be supplied continuously as an indispensable carbon source for denitrification reaction without sludge recycle and nitrified effluent recirculation. Fig. 4 shows the nitrogen removal characteristics of the biological phase separation process before and after application of the ceramic membrane module. When the process was operated at an HRT of $8 \mathrm{~h}$ and a cycle time of $4 \mathrm{~h}$, the concentrations of TKN, ammonia, and nitrate in the effluent from the biological phase separation process were shown to be in the range of $0-2.24 \mathrm{mg} / \mathrm{L}$ (average $0.74 \mathrm{mg} / \mathrm{L}$ ), $0-1.96 \mathrm{mg} / \mathrm{L}$ (average $0.40 \mathrm{mg} / \mathrm{L}$ ), and $4.64-11.48 \mathrm{mg} / \mathrm{L}$ (average $7.0 \mathrm{mg} / \mathrm{L}$ ), respectively. Whereas the process adopting membrane filtration was capable of producing TKN, ammonia,

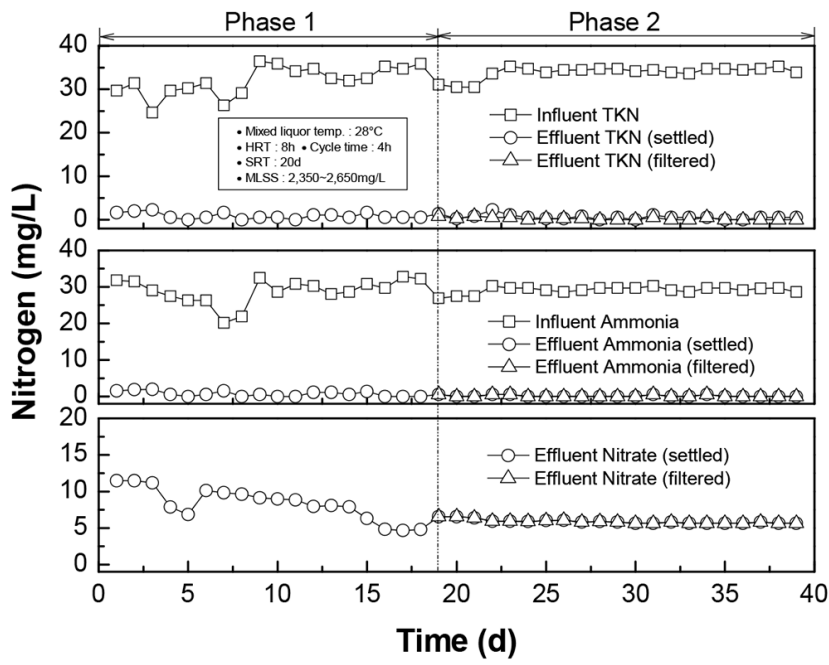

Fig. 4. Nitrogen removal characteristics of system. (Phase 1: system before membrane module application, Phase 2: system after membrane module application)

and nitrate in effluent ranging from 0-0.84 mg/L (average $0.24 \mathrm{mg} / \mathrm{L}$ ), 0-0.56 mg/L (average $0.13 \mathrm{mg} / \mathrm{L}$ ), and 5.63-6.55 mg/L (average 5.88 $\mathrm{mg} / \mathrm{L}$ ), respectively. It should be noted that additional TKN removal can be achieved successfully through the elimination of solids containing organic nitrogen in effluent by use of the ceramic membrane module. There is no ammonia removal regardless of ceramic membrane application, however, this may be explained by the fact that the ammonia nitrogen in water exists in the form of ammonium ion and free ammonia and they are in equilibrium.

Total nitrogen (TN) removal by this process was 45.4-85.1\% (average $75.9 \%$ ) at the operating conditions mentioned above, and effluent TN concentration ranged from 5.2-13.4 mg/L (average 7.7 $\mathrm{mg} / \mathrm{L})$. By using the ceramic membrane module, however, TN removal increased to the range of 70.7-85.3\% (average 80.5\%) and the process maintained an effluent TN below $10 \mathrm{mg} / \mathrm{L}$. This effluent TN concentration is less than or similar with other researchers' results [24-26] combining a membrane bioreactor or a membrane system with other unit processes. These results suggest that higher TN removal may be successfully achieved by a combination of the biological phase separation process with a ceramic microfiltration membrane.

\subsection{Filtration Characteristics}

Variations of total suspended solids (TSS) concentration and turbidity in effluent discharged from the biological phase separation process before and after application of the ceramic microfiltration membrane module are shown in Fig. 5. The turbidity in effluent was measured in the case of membrane filtration module application because the particles in effluent from the clarifier after general biological wastewater treatment settle quickly and do not contribute to a turbidity reading. The TSS concentration and turbidity in effluent of the biological phase separation process were 0.2-1.6 $\mathrm{mg} / \mathrm{L}$ (average $0.73 \mathrm{mg} / \mathrm{L}$ ) and 1.01-3.54 NTU (average $2.02 \mathrm{NTU}$ ), respectively, whereas the removal of particulate contaminants such as suspended solids and colloidal substances causing the turbidity 

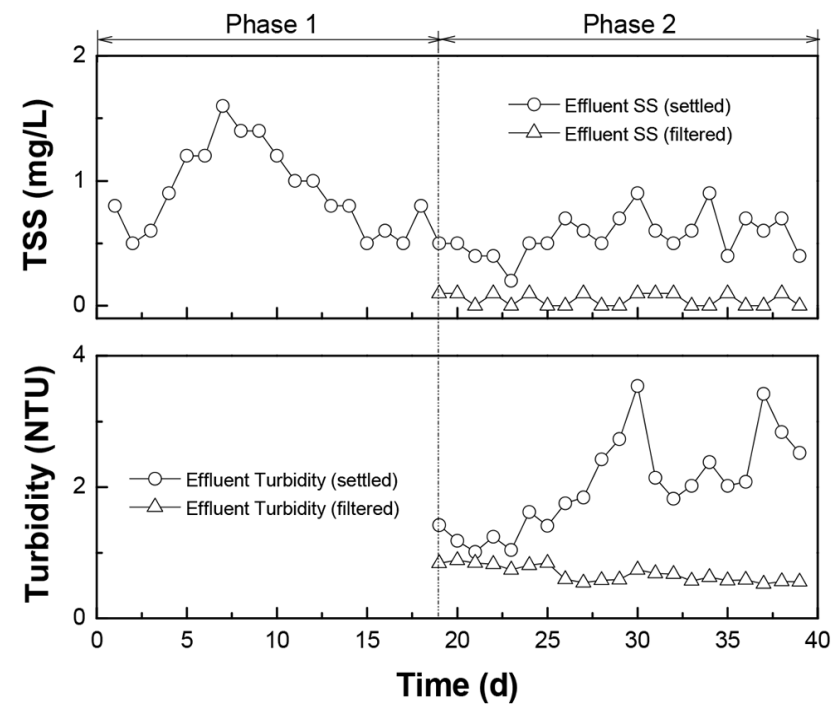

Fig. 5. Profiles of suspended solids and turbidity in effluent with/without ceramic membrane.

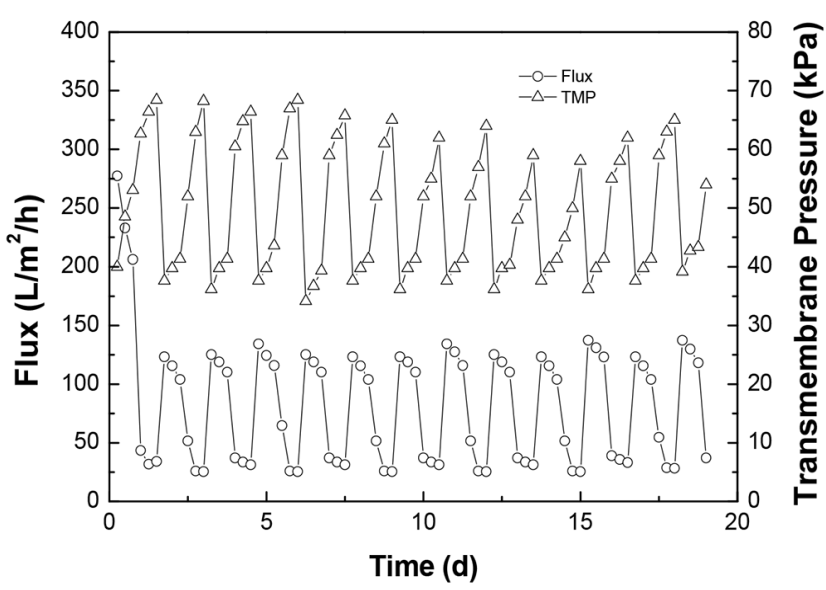

Fig. 6. Flux and TMP profile for filtration of settling tank effluent with ceramic membrane.

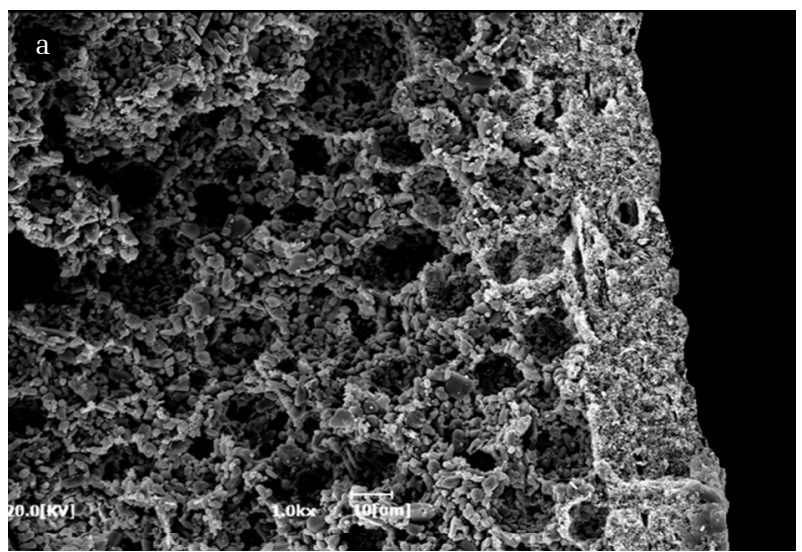

is noticeably improved after membrane filtration. The process adopting the ceramic microfiltration membrane module was capable of producing an effluent TSS ranging from $0.0-0.1 \mathrm{mg} / \mathrm{L}$ (average $0.047 \mathrm{mg} / \mathrm{L}$ ) and effluent turbidity as low as $0.524-0.884$ NTU (average $0.676 \mathrm{NTU}$ ).

In membrane filtration, flux stands for the flowrate of a property per unit area. TMP is defined as the pressure applied through the membrane. During phase 2, membrane filtration operated continuously. Fig. 6 presents the profiles of flux and TMP during the filtration procedure of the ceramic membrane. When the effluent from the clarifier of the biological treatment process was introduced to the ceramic microfiltration membrane, the flux sharply decreased from $280 \mathrm{~L} / \mathrm{m}^{2} / \mathrm{h}$ to $30 \mathrm{~L} / \mathrm{m}^{2} / \mathrm{h}$, and it was higher than the results of other studies [23, 27]. The TMP increased to $68.42 \mathrm{kPa}$, and the variation of TMP was similar with that of Hofs et al. [13]. In order to estimate the back-flushing cycle, the membrane surface was physically cleaned by washing the coated layer of the ceramic membrane, and this was conducted at the critical flux, defined as the permeate flux above which fouling appears. The back-flushing with water was carried out at $1.5 \mathrm{~d}$ intervals and it took about $10 \mathrm{~min}$. After back-flushing the membrane, the flux increased to $125-135 \mathrm{~L} / \mathrm{m}^{2} / \mathrm{h}$ and a TMP of $35.37 \mathrm{kPa}$ was observed. Steady values of the flux and TMP were maintained, and stable filtration was also achieved regardless of several back-flushings. This result shows that the filtration function of the ceramic membrane developed in this study may be recovered by physical cleaning such as by washing the coated layer, and this is more effective than the chemical cleaning method from an economical point of view.

Fig. 7 shows the SEM micrograph and the surface morphology of the ceramic membrane. As shown in Fig. 7(a), the surface of the membrane has a stably coated structure. As we can see from the cross-sectional micrograph of the membrane surface after filtration in Fig. 7(b), accumulation of solids and colloidal substances on the coated layer may also be observed. As mentioned above, however, fouling of the membrane surface may be controlled easily by physical cleaning.

\section{Conclusions}

A membrane module comprised of three tube-type ceramic mem-

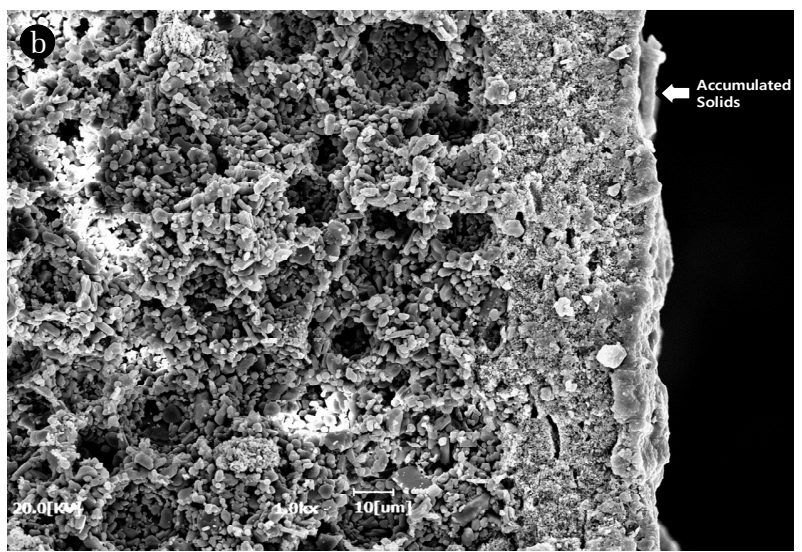

Fig. 7. Cross section of ceramic membrane. (a) Membrane before filtration (b) Membrane after filtration. 
branes for microfiltration was developed. It was also applied to biological phase separation processes for simultaneous removal of carbon and nitrogen, and its performance in post-treatment was evaluated. The manufacture of the tube-type ceramic membrane can successfully achieved by coating $\alpha$-alumina powder for formation of a microfiltration layer. The structure and boundary of the coated and support layers in the ceramic membrane were clearly observed. The removals of particulate contaminants such as suspended solids and colloidal substances were noticeably improved after membrane filtration.

Additional TKN removal was achieved through the elimination of solids containing organic nitrogen in effluent by use of the ceramic membrane module. The filtration function of the ceramic membrane developed in this study could be recovered by physical cleaning such as by washing the coated layer. It is more effective than the chemical cleaning method from an economical point of view. Thus, this proposed system is an alternative and flexible option for existing biological nutrient removal processes suffering from poor settling performance due to the use of a clarifier.

\section{Acknowledgments}

This research was supported by Materials and Membranes (M\&Ms) Co., Ltd. in Korea.

\section{References}

1. Paerl HW, Xu H, McCarthy MJ, et al. Controlling harmful cyanobacterial blooms in a hyper-eutrophic lake (Lake Taihu, China): The need for a dual nutrient (N \& P) management strategy. Water Res. 2011;45:1973-1983.

2. Smith VH, Schindler DW. Eutrophication science: Where do we go from here? Trends Ecol. Evol. 2009;24:201-207.

3. Smith VH. Eutrophication of freshwater and coastal marine ecosystems: A global problem. Environ. Sci. Pollut. Res. 2003;10:126-139.

4. Tong J, Chen Y. Enhanced biological phosphorus removal driven by short-chain fatty acids produced from waste activated sludge alkaline fermentation. Environ. Sci. Technol. 2007;41:7126-7130.

5. Lewis WM, Wurtsbaugh WA, Paerl HW. Rationale for control of anthropogenic nitrogen and phosphorus to reduce eutrophication of inland waters. Environ. Sci. Technol. 2011;45:10300-10305.

6. Tchobanoglous G, Stensel HD, Tsuchihashi R, Burton F. Wastewater engineering: Treatment and resource recovery. 5th ed. New York: McGraw-Hill, Inc.; 2014.

7. Dotro G, Jefferson G, Jones M, Vale P, Cartmell E, Stephenson T. A review of the impact and potential of intermittent aeration on continuous flow nitrifying activated sludge. Environ. Technol. 2011;31:1685-1697.

8. Hanhan O, Insel G, Yagci NO, Artan N, Orhon D. Mechanism and design of intermittent aeration activated sludge process for nitrogen removal. J. Environ. Sci. Health Part A 2011;46:9-16.

9. Yilmaz G, Lemaire R, Keller J, Yuan Z. Effectiveness of an alternating aerobic, anoxic/anaerobic strategy for maintaining biomass activity of BNR sludge during long-term starvation. Water Res. 2007;41:2590-2598.

10. Irizar I, Suescun J, Plaza F, Larrea L. Optimizing nitrogen removal in the BioDenitro process. Water Sci. Technol. 2003;48: 429-436

11. Hua FL, Tsang YF, Wang YJ, Chan SY, Chua H, Sin SN. Performance study of ceramic microfiltration membrane for oily wastewater treatment. Chem. Eng. J. 2007;128:169-175.

12. Melin T, Jefferson B, Bixio D, et al. Membrane bioreactor technology for wastewater treatment and reuse. Desalination 2006;187:271-282.

13. Hofs B, Ogier J, Vries D, Beerendonk EF, Cornelissen ER. Comparison of ceramic and polymeric membrane permeability and fouling using surface water. Sep. Purif. Technol. 2011;79:365-374.

14. Barredo-Damas S, Alcaina-Miranda MI, Bes-Pia A, Iborra-Clar MI, Iborra-Clar A, Mendoza-Roca JA. Ceramic membrane behavior in textile wastewater ultrafiltration. Desalination 2010;250: 623-628.

15. Lehman SG, Liu L. Application of ceramic membranes with pre-ozonation for treatment of secondary wastewater effluent. Water Res. 2009;43:2020-2028.

16. Oh HK, Takizawa S, Ohgaki S, Katayama H, Oguma K, Yu MJ. Removal of organics and viruses using hybrid ceramic MF system without draining PAC. Desalination 2007;202:191-198.

17. Barredo-Damas S, Alcaina-Miranda MI, Iborra-Clar MI, Bes-Pia A, Mendoza-Roca JA, Iborra-Clar A. Study of the UF process as pretreatment of NF membranes for textile wastewater reuse. Desalination 2006;200:745-747.

18. Lee S, Cho J. Comparison of ceramic and polymeric membranes for natural organic matter (NOM) removal. Desalination 2004;160:223-232.

19. Weber R, Chmiel H, Mavrov V. Characteristics and application of new ceramic nanofiltration membranes. Desalination 2003; 157:113-125.

20. American Public Health Association, American Water Works Association, Water Environment Federation. Standard methods for the examination of water and wastewater. 22nd ed. Washington D.C.: American Public Health Association; 2012.

21. Chon K, Kyongshon H, Cho J. Membrane bioreactor and nanofiltration hybrid system for reclamation of municipal wastewater: Removal of nutrients, organic matter and micropollutants. Bioresour. Technol. 2012;122:181-188.

22. Liang Z, Das A, Beerman D, Hu Z. Biomass characteristics of two types of submerged membrane bioreactors for nitrogen removal from wastewater. Water Res. 2010;44;3313-3320.

23. Monclús H, Sipma J, Ferrero G, Rodriguez-Roda I, Comas J. Biological nutrient removal in an MBR treating municipal wastewater with special focus on biological phosphorus removal. Bioresour. Technol. 2010;101:3984-3991.

24. Liu Q, Wang XC. Mechanism of nitrogen removal by a hybrid membrane bioreactor in municipal wastewater treatment. Desalin. Water Treat. 2014;52:5165-5171.

25. Ding A, Qu F, Liang H, et al. A novel integrated vertical membrane bioreactor (IVMBR) for removal of nitrogen from synthetic wastewater/domestic sewage. Chem. Eng. J. 2013;223:908-914. 26. Guo W, Ngo HH, Palmer CG, Xing W, Hu AYJ, Listowski A. 
Roles of sponge sizes and membrane types in a single stage sponge-submerged membrane bioreactor for improving nutrient removal from wastewater for reuse. Desalination 2009;249:672-676.
27. Wei CH, Huang X, Aim RB, Yamamoto K, Amy G. Critical flux and chemical cleaning-in-place during the longterm operation of a pilot-scale submerged membrane bioreactor for municipal wastewater treatment. Water Res. 2011;45:863-871. 